Check for updates

Cite this: RSC Adv., 2017, 7, 27243

Received 7th March 2017

Accepted 18th May 2017

DOI: $10.1039 / \mathrm{c} 7 \mathrm{ra0} 2758 \mathrm{c}$

rsc.li/rsc-advances

\section{Highly efficient synthesis of unsymmetrical 1,3- diynes from organoalane reagents and alkynyl bromides mediated by a nickel catalyst $\uparrow$}

\author{
Song Mo, Xue-Bei Shao, Gang Zhang and Qing-Han Li (iD) *
}

\begin{abstract}
Highly efficient and simple cross-coupling reactions of alkynylbromides with organoalane reagents for the synthesis of unsymmetrical 1,3-diynes derivatives using $\mathrm{Ni}(\mathrm{OAc})_{2}(2-5 \mathrm{~mol} \%) /(\mathrm{o} \text {-furyl })_{3} \mathrm{P}(4-10 \mathrm{~mol} \%)$ as a catalyst are reported. Excellent yields (up to 94\%) were obtained for a wide range of substrates at $\mathrm{rt}$ or $60{ }^{\circ} \mathrm{C}$ for $2-3 \mathrm{~h}$ in $\mathrm{Et}_{2} \mathrm{O}$ or toluene.
\end{abstract}

Diynes have been widely used in organic synthesis due to their significance as building blocks. ${ }^{1}$ Amongst them, conjugated 1,3diynes have significant applications in the preparation of natural products, ${ }^{2}$ pharmaceuticals, ${ }^{3} \pi$-conjugated acetylenic polymers, ${ }^{4}$ advanced materials ${ }^{5}$ and heterocyclic compounds, ${ }^{6}$ as well as in electronic and optical materials, ${ }^{7}$ and elsewhere. ${ }^{8}$ In addition, 1,3-diynes are common structural motifs found in pharmaceutically and biologically active compounds, which are known to have antifungal, ${ }^{9}$ antibacterial, ${ }^{10}$ anti-inflammatory,${ }^{11}$ anti-HIV ${ }^{12}$ and anticancer properties. ${ }^{13}$ Thus, their synthesis and applications has attracted a great amount of attention over the past few decades. Since the discovery of the Glaser homocoupling reaction of terminal alkynes in $1869,{ }^{14}$ a great amount of attention has been given to the development of new and efficient procedures for the synthesis of conjugated 1,3diyne derivatives. Recently, a variety of processes have been developed for the preparation of conjugated 1,3-diynes, typical synthetic protocols including the cross-coupling reactions of 1haloalkynes with terminal alkynes, ${ }^{15}$ cross-coupling reactions of terminal alkynes, ${ }^{16}$ cross-coupling reaction of terminal alkynes with 1,2-dihaloalkenes, ${ }^{17}$ cross-coupling of alkynylsilanes with haloalkynes, ${ }^{18}$ conjugated diynones decarbonylation reaction, ${ }^{19}$ cross-coupling reactions of aryl iodides and alkynyl acid, ${ }^{20}$ oxidative coupling of alkynyl Grignard reagents, ${ }^{21}$ oxidative decarboxylative homo-coupling of alkynyl acids, ${ }^{22}$ oxidative homo-coupling reactions of terminal alkynes with the oxidants, ${ }^{23}$ homo-coupling of alkynyltellurides, ${ }^{24}$ haloalkynes,${ }^{25}$ and alkynylsilanes. ${ }^{26}$

Despite that, these efforts have provided alternative methods for the synthesis of conjugated 1,3-dyines. However, these reactions still suffer from excess oxidants, excess bases,

College of Chemistry and Environmental Protection Engineering, Southwest University for Nationalities, Chengdu 610041, P. R. China. E-mail: lqhchem@163.com; Fax: +8628-85524382

$\dagger$ Electronic supplementary information (ESI) available. See DOI: $10.1039 / \mathrm{c} 7 \mathrm{ra} 02758 \mathrm{c}$ cocatalysts, high temperature, relatively long reaction times, and the special reaction medium. The development of more efficient and atom economical approaches for the synthesis of conjugated 1,3-diynes remains as desirable work. In addition to the above reagents, alkynylaluminum reagents have been extensively used as nucleophiles for organic reactions. ${ }^{27}$

In recent times, metal-catalyzed cross-coupling reactions of electrophiles with alkynylmetallic reagents have provided an alternative route for the preparation of alkyne compounds. ${ }^{28}$ Previous studies show that organoalanes reagents are a highly efficient nucleophiles for cross-coupling reactions with aromatic halides ${ }^{29}$ or benzylic halides ${ }^{30}$ and investigations have demonstrated that nickel is a good catalytic metal. ${ }^{31}$ To continue our efforts in developing coupling reactions using reactive organometallic reagents, ${ }^{29,30,32}$ we report a novel nickel(II)-catalyzed cross-coupling of alkynylhalides with alkynylaluminum reagents at ambient temperature or $60{ }^{\circ} \mathrm{C}$ in a short time with good isolated yield for the synthesis of unsymmetrical conjugated 1,3-diynes (Scheme 1).

In order to optimize the reaction conditions, effects of phosphine ligand, nickel source, reaction time, solvent, the amount of organoalanes reagents, and the molar ratio of metal to ligand on the cross-coupling reaction were investigated using alkynylaluminum and alkynyl bromide as a model system. The reaction of diethyl(2-phenylethynyl)aluminum $\left(\mathrm{C}_{6} \mathrm{H}_{5} \mathrm{C} \equiv \mathrm{CAlEt}_{2}\right)$ (1a) with 1-(2-bromo-ethynyl)-4-methylbenzene $\left(p-\mathrm{MeC}_{6} \mathrm{H}_{5^{-}}\right.$ $\mathrm{C} \equiv \mathrm{CBr}$ ) (2a) using a nickel catalyst of phosphine (eqn (1)) was first examined. Under the optimized conditions of $2 \mathrm{~mol} \%$ $\mathrm{Ni}(\mathrm{OAc})_{2}$ and $4 \mathrm{~mol} \% \mathrm{P}(o \text {-furyl })_{3}$ conducting in diethyl ether at room temperature over $2 \mathrm{~h}$, producing $3 \mathrm{aa}$ in $87 \%$ isolated yield (ESI: Tables S1 and S2 $\dagger$ ).

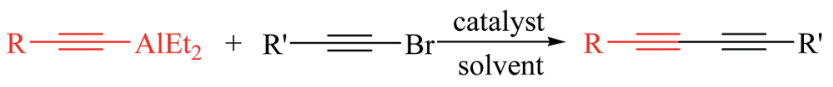

Scheme 1 Metal-catalyzed coupling reactions of 1-haloalkynes derivatives with organoalanes nucleophiles. 


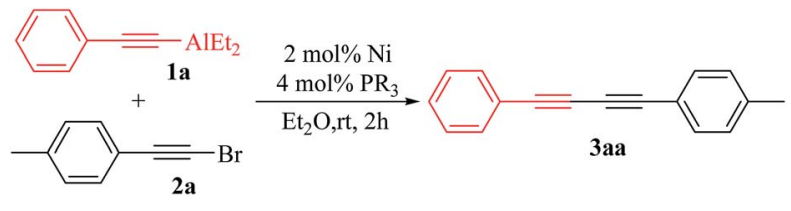

Generalities of the catalytic system were examined with various 1-bromoalkynes derivatives (eqn (2)), and the results were summarized in Table 1. As shown in Table 1, various 1bromoalkynes derivatives bearing electron-withdrawing or electron-donating substituents were smoothly coupled to give the corresponding unsymmetrical conjugated 1,3-diynes 3 in $64-94 \%$ isolated yield (Table 1, entries 1-14). The crosscoupling reaction with 1-bromoalkynes bearing an electronwithdrawing group, such as fluoro, chloro, bromo and trifluoromethyl groups, or electron-donating group, such as methyl, ethyl, propyl and tertbutyl groups, produced the conjugated products 1,3-diyne in good to excellent yield (Table 1, entries 1-12). In particular, the cross-coupling of 1-bromo-4(2-bromoethynyl) benzene (2g) with diethyl-(2-phenylethynyl) aluminum (1a) could also be selectively obtained the unsymmetrical conjugated 1,3-diynes $3 \mathrm{ag}$ in $74 \%$ isolated yield (Table 1, entry 7). However, the cross-coupling reaction of diethyl-(2phenylethynyl)aluminum (1a) with 1-(2-bromoethynyl)-4methoxybenzene (4- $\mathrm{MeOC}_{6} \mathrm{H}_{5} \mathrm{C} \equiv \mathrm{CBr}$ ) (2f) only gave products of unsymmetrical conjugated 1,3-diyne 3af in $64 \%$ isolated yield (Table 1, entry 6) potentially due to the 1-(2-bromoethynyl)-4-

Table 1 Nickel-catalyzed cross-coupling reactions of $\mathrm{C}_{6} \mathrm{H}_{5} \mathrm{C} \equiv \mathrm{CAlEt}_{2}$ (1a) with various 1-bromoalkynes (2) ${ }^{a}$

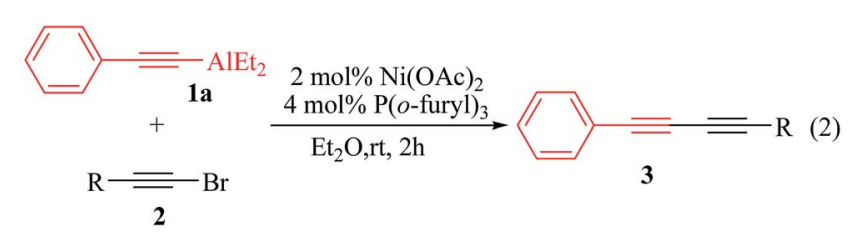

\begin{tabular}{|c|c|c|c|}
\hline Entry & 1-Bromoalkynes 2 & $\begin{array}{l}\text { Product } \\
\mathbf{3}\end{array}$ & Yield $^{b}(\%$ \\
\hline 1 & 4-Me-Ph (2a) & $3 \mathbf{a a}$ & 87 \\
\hline 2 & 4-Et-Ph (2b) & $3 \mathbf{a b}$ & 85 \\
\hline 3 & 4-Propyl-Ph (2c) & 3ac & 86 \\
\hline 4 & $4-{ }^{t} \mathrm{Bu}-\mathrm{Ph}(\mathbf{2 d})$ & 3ad & 84 \\
\hline 5 & 3-Me-Ph (2e) & 3ae & 81 \\
\hline 6 & 4-MeO-Ph (2f) & 3af & 64 \\
\hline 7 & 4-Br-Ph (2g) & $3 a g$ & 74 \\
\hline 8 & 4-Cl-Ph (2h) & $3 \mathbf{a h}$ & 82 \\
\hline 9 & $4-\mathrm{F}-\mathrm{Ph}(2 \mathbf{i})$ & 3ai & 90 \\
\hline 10 & 3-F-Ph (2j) & 3aj & 93 \\
\hline 11 & 2-F-Ph (2k) & 3ak & 86 \\
\hline 12 & $4-\mathrm{CF}_{3}-\mathrm{Ph}(2 \mathrm{l})$ & 3al & 92 \\
\hline 13 & 2-Pyridinyl (2m) & 3am & 94 \\
\hline 14 & 2-Thienyl (2n) & 3an & 83 \\
\hline 15 & 4-CN-Ph (2o) & $3 \mathbf{a o}$ & $<5 \%$ \\
\hline 16 & $4-\mathrm{CH}_{3} \mathrm{OOC}-\mathrm{Ph}(2 \mathrm{p})$ & 3ap & 0 \\
\hline
\end{tabular}

${ }^{a} \mathbf{1 a} / 2=1.0 / 0.5 \mathrm{mmol} ; 2 \mathrm{~mL} \mathrm{Et} 2 \mathrm{O}$; room temperature; 2 h. ${ }^{b}$ Isolated yield. methoxybenzene was being decreased by methoxyl group. More importantly, 2-(2-bromoethynyl)pyridine and 2-(2-bromoethynyl)thiophene reagents were also effective substrates for this reaction, giving the corresponding coupling products of unsymmetrical conjugated 1,3-diynes 3am and 3an in 83\% and $94 \%$ isolated yield, respectively (Table 1, entries 13 and 14). Unfortunately, cross-coupling reaction of 4-(2-bromoethynyl)benzonitrile (2o) $\quad\left(p-\mathrm{CNC}_{6} \mathrm{H}_{5} \mathrm{C} \equiv \mathrm{CBr}\right) \quad$ and diethyl-(2phenylethynyl)-aluminum (1a) $\left(\mathrm{C}_{6} \mathrm{H}_{5} \mathrm{C} \equiv \mathrm{CAlEt}_{2}\right)$ only gave products of unsymmetrical conjugated 1,3-diyne 3 ao in $5 \%$ yield (Table 1, entries 15). While, coupling of methyl 4-(2-bromoethynyl)benzoate $(2 \mathbf{p})\left(p-\mathrm{CH}_{3} \mathrm{OOCC}_{6} \mathrm{H}_{5} \mathrm{C} \equiv \mathrm{CBr}\right)$ could not produce the target compound (Table 1, entries 16).

We subsequently investigated cross-coupling reactions of substituted aryl alkynylaluminum reagents with various 1-bromoalkynes. However, the cross-coupling reaction of diethyl(2(4-methoxy phenyl)-ethynyl)aluminum $\left(4-\mathrm{MeOC} \equiv \mathrm{CAlEt}_{2}\right)(\mathbf{1 b})$ with 1-(2-bromo-ethynyl)-benzene (2o) employing the catalyst of $2 \mathrm{~mol} \% \mathrm{Ni}(\mathrm{OAc})_{2}$ and $4 \mathrm{~mol} \% \mathrm{P}(o \text {-furyl })_{3}$ yielded coupling products of unsymmetrical conjugated 1,3-diyne 3 bo with only a $62 \%$ isolated yield. Therefore, the reaction conditions were retuned, and the best performed catalyst was found to be $5 \mathrm{~mol} \%$ $\mathrm{Ni}(\mathrm{OAc})_{2}$ and $10 \mathrm{~mol} \% \mathrm{P}(o \text {-furyl })_{3}$ while the reaction was conducting in toluene at $60{ }^{\circ} \mathrm{C}$ for $3 \mathrm{~h}$ (ESI Table S3†), furnishing 3 bo with $75 \%$ isolated yield.

The reaction scope was further explored on substrates of $\mathrm{R}^{\prime} \mathrm{C} \equiv \mathrm{CAlEt}_{2}\left(\mathrm{R}^{\prime}=4-\mathrm{MeOPh}(\mathbf{1 b})\right.$ or 4-FPh (1c), 4-MePh (1d)) and various 1-bromoalkynes using $5 \mathrm{~mol} \% \mathrm{Ni}(\mathrm{OAc})_{2}$ and $10 \mathrm{~mol} \%$ $\mathrm{P}(o \text {-furyl })_{3}$ conducting in toluene at $60{ }^{\circ} \mathrm{C}$ for $3 \mathrm{~h}$ (eqn (3)), and results are summarized in Table 2 . Satisfactory application scope was demonstrated by this section of experiment. The cross-coupling reaction can be applied to $\mathrm{C}(\mathrm{sp})-\mathrm{C}(\mathrm{sp})$ bond formations, affording the coupling products unsymmetrical conjugated 1,3-diynes in 51-80\% isolated yield (Table 2, 1-15). Cross-coupling reactions of substituted aryl alkynylaluminum reagents $\mathbf{1 b}$ or $1 \mathbf{c}$ or $1 \mathbf{d}$ with 1-bromoalkyne reagents containing different functional groups such as alkyl, halides (2a, $2 \mathbf{g}, \mathbf{2 h}, \mathbf{2} \mathbf{i}$, $2 \mathbf{j}, 2 \mathbf{k}, 2 \mathbf{l}$ ) could potentially couple, giving the corresponding unsymmetrical conjugated 1,3-diynes moderate to good isolated yields (Table 2, entries 1-4, 7, 8, 10-14). Furthermore, 2-(2bromoethynyl)thiophene (2n) reacted successfully with diethyl(2-(4-methoxyphenyl)ethynyl)aluminum (4$\left.\mathrm{MeOPhC} \equiv \mathrm{C}-\mathrm{AlEt}_{2}\right)(\mathbf{1 b})$ to provide unsymmetrical conjugated 1,3-diyne 3 bn with $74 \%$ isolated yield (Table 2 , entry 5 ). The 2 -(4$p$-tolylbuta-1,3-diynyl)pyridine (3dm) resulting from 2-(2bromo-ethynyl)pyridine (2m) and diethyl(2-p-tolyl-ethynyl) aluminum (4-MePhC $\equiv \mathrm{CAlEt}_{2}$ ) (1d) was obtained with $72 \%$ isolated yield (Table 2, entry 15). While, the cross-coupling reaction of diethyl(2-(4-fluorophenyl)-ethynyl) aluminium (4$\mathrm{FPhC} \equiv \mathrm{CAlEt}_{2}$ ) (1c) with 1-bromo-hept-1-yne (2p) gave the corresponding unsymmetrical conjugated 1,3-diyne 3cp with a 51\% isolated yield (Table 2, entry 9). Unfortunately, crosscoupling of 1-(2-bromoethynyl)-4-methylbenzene (2a) $\left(p-\mathrm{CH}_{3}-\right.$ $\mathrm{C}_{6} \mathrm{H}_{5} \mathrm{C} \equiv \mathrm{CBr}$ ) and $\operatorname{diethyl}(2-(4-m e t h y l b e n z o a t e)$ ethynyl) aluminium (4-MeOOCPhC $\equiv \mathrm{CAlEt}_{2}$ ) (1e) could not produce the coupling product (Table 2, entries 16). 
Table 2 Cross-coupling reactions of substituted aryl organoalanes reagents $\mathrm{ArC} \equiv \mathrm{CAlEt}_{2}$ (1) with various 1-bromoalkynes (2) ${ }^{a}$

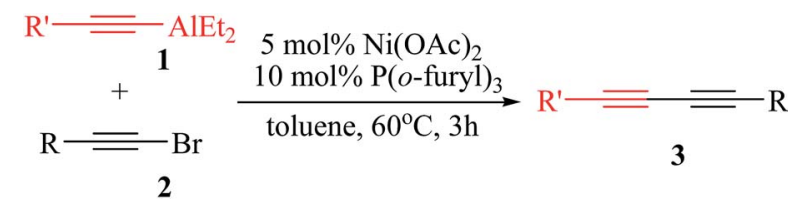

\begin{tabular}{|c|c|c|c|c|}
\hline Entry & $1 \mathrm{R}^{\prime}$ & $2 \mathrm{R}$ & Product & Yield $^{b}(\%)$ \\
\hline 1 & 4-MeOPh (1b) & 4-MePh (2a) & $3 \mathbf{b a}$ & 62 \\
\hline 2 & 4-MeOPh (1b) & $4-\mathrm{ClPh}(\mathbf{2 h})$ & $3 \mathbf{b h}$ & 72 \\
\hline 3 & 4-MeOPh (1b) & $4-\mathrm{FPh}(2 \mathbf{i})$ & $3 \mathbf{b i}$ & 71 \\
\hline 4 & 4-MeOPh (1b) & $3-\mathrm{FPh}(2 \mathrm{j})$ & $3 \mathbf{b j}$ & 72 \\
\hline 5 & 4-MeOPh (1b) & 2-Thienyl (2n) & 3bn & 74 \\
\hline 6 & 4-MeOPh (1b) & $\mathrm{Ph}(20)$ & 3bo & 75 \\
\hline 7 & $4-\mathrm{FPh}(1 \mathrm{c})$ & $3-\mathrm{FPh}(2 \mathbf{j})$ & $3 c j$ & 55 \\
\hline 8 & 4-FPh (1c) & $2-\mathrm{FPh}(\mathbf{2 k})$ & $3 \mathrm{ck}$ & 53 \\
\hline 9 & $4-\mathrm{FPh}(1 \mathrm{c})$ & $n$-Pentyl (2p) & $3 \mathrm{cp}$ & 51 \\
\hline 10 & 4-MePh (1d) & 4-BrPh (2g) & $3 d g$ & 68 \\
\hline 11 & 4-MePh (1d) & $4-\mathrm{FPh}(2 \mathbf{i})$ & $3 d i$ & 62 \\
\hline 12 & 4-MePh (1d) & $3-\mathrm{FPh}(2 \mathbf{j})$ & 3dj & 73 \\
\hline 13 & 4-MePh (1d) & $2-\mathrm{FPh}(\mathbf{2 k})$ & $3 \mathrm{dk}$ & 80 \\
\hline 14 & 4-MePh (1d) & $4-\mathrm{CF}_{3} \mathrm{Ph}(2 \mathrm{l})$ & 3dl & 75 \\
\hline 15 & $4-\mathrm{MePh}(\mathbf{1 d})$ & 2-Pyridinyl (2m) & $3 \mathrm{dm}$ & 72 \\
\hline 16 & 4-MeOOCPh (1e) & 4-MePh (2a) & 3af & 0 \\
\hline
\end{tabular}

The cross-coupling reactions of aliphatic alkynylaluminum reagents with various 1-bromoalkynes was also investigated under the same catalytic system. The unsymmetrical conjugated 1,3-diyne 3fo was obtained with 52\% isolated yield when 1-(2-bromoethynyl)-benzene (2o) coupled with the TMSC $\equiv$ CAlEt $_{2}$ (1f) nucleophile. However, the cross-coupling reaction of 1-(2-bromoethynyl)-benzene (2o) coupled with the $\mathrm{TMSC} \equiv \mathrm{CAlEt}_{2}$ (1f) favoured a formation of the unsymmetrical conjugated 1,3-diyne 3fo with $80 \%$ isolated yield in DME at room temperature for $3 \mathrm{~h}$ (ESI Table $\mathrm{S} 4 \dagger$ ). So, the reaction scope was further explored on substrates of TMSC $\equiv$ CAlEt $_{2}$ (1f) and various 1-bromoalkynes using $5 \mathrm{~mol} \% \mathrm{Ni}(\mathrm{OAc})_{2}$ and $10 \mathrm{~mol} \%$ $\mathrm{P}(o \text {-furyl })_{3}$ conducting in DME at room temperature for $3 \mathrm{~h}$ (eqn (4)), and results are summarized in Table 3. As shown in Table 3 , various 1-bromoalkynes derivatives bearing electronwithdrawing or electron-donating substituents were smoothly coupled to give the corresponding unsymmetrical conjugated 1,3-diynes 3 in 67-80\% isolated yield (Table 3, entries 1-6). The cross-coupling reaction with 1-bromoalkynes bearing an electron-withdrawing group, such as fluoro and trifluoromethyl groups, or electron-donating group, such as methoxyl and tertbutyl groups, produced the conjugated products 1,3-diyne in good isolated yield (Table 3 , entries 2-5). In particular, the cross-coupling of 2-(2-bromoethynyl)naphthalene (2q) with TMSC $\equiv$ CAlEt $_{2}$ (1f) could also be obtained the conjugated 1,3diynes $\mathbf{3 f q}$ in $74 \%$ isolated yield (Table 3 , entry 6 ).

The effect of the alkylhalides and dummy ligand of organoalane reagents on the reaction were investigated, and the results were summarized in Table 4. As shown in Table 4, cross-
Table 3 Cross-coupling reactions of organoalanes reagents $\mathrm{TMSC} \equiv \mathrm{CAlEt}_{2}$ (1f) with various 1-bromoalkynes (2) ${ }^{a}$

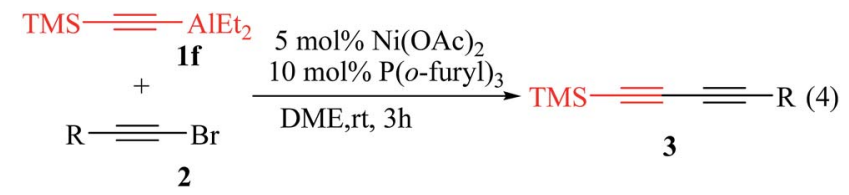

\begin{tabular}{llll}
\hline Entry & 2 R & Product & Yield $^{b}(\%)$ \\
\hline 1 & $\mathrm{Ph} \mathrm{(2o)}$ & $\mathbf{3 f o}$ & 80 \\
2 & $4-{ }^{t} \mathrm{Bu}-\mathrm{Ph}(\mathbf{2 d})$ & $\mathbf{3 f d}$ & 74 \\
3 & $4-\mathrm{MeOPh}(\mathbf{2 f})$ & $\mathbf{3 f f}$ & 76 \\
4 & $4-\mathrm{FPh}(\mathbf{2 i})$ & $\mathbf{3 f i}$ & 72 \\
5 & $4-\mathrm{CF}_{3} \mathrm{Ph}(\mathbf{2 l})$ & $\mathbf{3 f l}$ & 67 \\
6 & 2-Naphthyl (2q) & $\mathbf{3 f q}$ & 74 \\
${ }^{a} \mathbf{1 / 2}=1.0 / 0.5$ & mmol; $2 \mathrm{~mL} \mathrm{DME;}$ room temperature; 3 h. $^{b}$ Isolated \\
yield. & &
\end{tabular}

coupling reaction of dimethyl-(2-phenylethynyl)-aluminum (1g) $\left(\mathrm{C}_{6} \mathrm{H}_{5} \mathrm{C} \equiv \mathrm{CAlMe}_{2}\right)$ with $p-\mathrm{CH}_{3} \mathrm{C}_{6} \mathrm{H}_{5} \mathrm{C} \equiv \mathrm{CBr} \quad$ (2a) gave product of unsymmetrical conjugated 1,3-diyne 3aa in $68 \%$ isolated yield (Table 4, entry 1). The coupling reaction of propargyl iodide (2q) with diethyl-(2-phenylethynyl)-aluminum (1a) $\left(\mathrm{C}_{6} \mathrm{H}_{5} \mathrm{C} \equiv \mathrm{CAlEt}_{2}\right)$ gave product of unsymmetrical conjugated 1,3-diyne 3 aa in a $75 \%$ isolated yield (Table 4 , entry 2). While, coupling of propargyl chloride (2r) gave coupling product 3aa in only $48 \%$ isolated yield (Table 4 , entry 3 ). Gratifyingly, $70 \%$ isolated yield of product 3aa was obtained using tri(2phenylethynyl)-aluminum (1h) as nucleophiles (Table 4, entry 4). The results showed that the different alkylhalides and dummy ligand of organoalane reagents are compatible with this procedure.

While a precise understanding of the reaction mechanism awaits further study, a plausible catalytic pathway is proposed in Scheme 2. The first step is the oxidative addition of 1-bromoalkyne (1) to $\mathrm{Ni}(0)$ phosphine complex (4) (which in turn from $\mathrm{Ni}(\mathrm{OAc})_{2}$ and $\mathrm{R}^{\prime} \mathrm{C} \equiv \mathrm{CAlEt}_{2}$ (2) reagents) that forms the

Table 4 The effect of the alkylhalides and dummy ligand of organoalane reagents on the reaction ${ }^{a}$

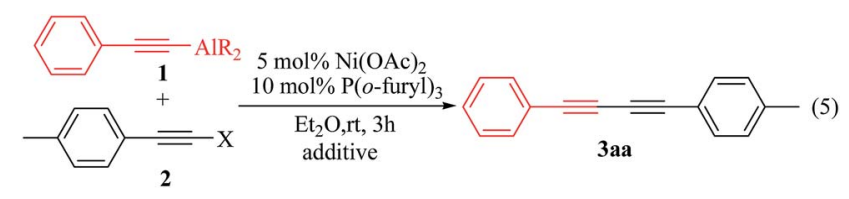

\begin{tabular}{lllll}
\hline Entry & R (1) & X (2) & Product & Yield $^{b}(\%)$ \\
\hline 1 & Me (19) & Br (2a) & 3aa & 68 \\
2 & Et (1a) & I (2q) & 3aa & 75 \\
3 & Et (1a) & Cl (2r) & 3aa & 48 \\
4 & PhC $\equiv$ C- (1h) & Br (2a) & 3aa & 70
\end{tabular}

${ }^{a} \mathbf{1} / \mathbf{2}=1.0 / 0.5 \mathrm{mmol} ; 2 \mathrm{~mL} \mathrm{Et}{ }_{2} \mathrm{O}$; room temperature; 3 h. ${ }^{b}$ Isolated yield. 


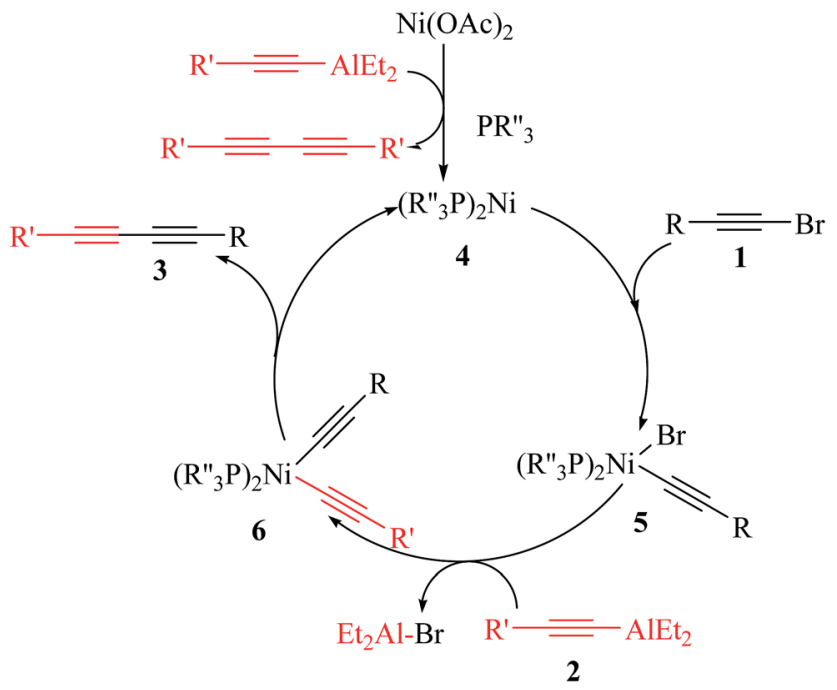

Scheme 2 The proposed catalytic cycle for the formation of unsymmetrical conjugated 1,3-diyne 3 .

organonickel(II) bromide intermediate (5). Transmetalation of $\mathrm{R}^{\prime} \mathrm{C} \equiv \mathrm{CAlEt}_{2}$ (2) with 5 gives alkyne-alkynenickelium(II) intermediate (6) and $\mathrm{Et}_{2} \mathrm{AlBr}$. Finally, complex 6 under goes reductive elimination to afford the desired cross-coupling product 3 and regenerate the active $\mathrm{Ni}(0)$ species for the next catalytic cycle.

\section{Conclusions}

In conclusion, a novel nickel-catalyzed cross-coupling reaction of 1-bromoalkynes with alkynylaluminum reagents is reported. A variety of 1-bromoalkynes with aryl, heterocycloyl, or alkyl group can be efficiently coupled to give the corresponding coupling products unsymmetrical conjugated 1,3-diynes in good yield and with good functional group compatibility. Moreover, the ready availability of the starting materials, the mild reaction conditions, and the simplicity of the operations involved are additional features making the methodology could therefore serve as a complementary option in the field of conjugated 1,3-diyne synthesis. A possible catalytic cycle was proposed to explain the formation of the products conjugated 1,3-diynes. Further application of these conjugated 1,3-diynes in organic synthesis are underway.

\section{Acknowledgements}

The authors are grateful to the Sichuan Provincial Department of science and technology support program (No. 2015NZ0033), and the Postgraduate Degree Construction Project of Southwest University for Nationalities (No. CX2016SZ063) for financial support.

\section{Notes and references}

1 (a) Y. Matsuda, S. Naoe, S. Oishi, N. Fujii and H. Ohno, Chem.-Eur. J., 2015, 21, 1463; (b) Y. G. Zhu and Y. A. Shi, Org. Biomol. Chem., 2013, 11, 7451.
2 (a) A. L. K. Shi Shun and R. R. Tykwinski, Angew. Chem., Int. Ed., 2006, 45, 1034; (b) H. Yun, T. C. Chou, H. J. Dong, Y. Tian, Y. M. Li and S. J. Danishefsky, J. Org. Chem., 2005, 70, 10375.

3 (a) M. L. Lerch, M. K. Harper and D. J. Faulkner, J. Nat. Prod., 2003, 66, 667; (b) K. C. Nicolau, P. G. Bulger and D. Sarlah, Angew. Chem., Int. Ed., 2005, 44, 4490.

4 (a) B. J. Morgan, X. Xie, P. W. Phuan and M. C. Kozlowski, J. Org. Chem., 2007, 72, 6171; (b) F. Babudri, D. Colangiuli, P. A. Di Lorenzo, G. M. Farinola, O. H. Omar and F. Naso, Chem. Commun., 2003, 130.

5 (a) Acetylene Chemistry: Chemistry, Biology and Material Science, ed. F. Diederich, P. J. Stang and R. R. Tykwinski, Wiley-VCH GmbH KGaA, Weinheim, Germany, 2005; (b) M. Gholami and R. R. Tykwinski, Chem. Rev., 2006, 106, 4997.

6 (a) V. Lavallo, G. D. Frey, B. Donnadieu, M. Soleilhavoup and G. Bertrand, Angew. Chem., Int. Ed., 2008, 47, 5224; (b) T. Matsuda, S. Kadowaki and M. Murakami, Chem. Commun., 2007, 2627.

7 (a) J. A. Marsden and M. M. Haley, J. Org. Chem., 2005, 70, 10213; (b) S. Eisler, A. D. Slepkov, E. Elliott, T. Luu, R. McDonald, F. A. Hegmann and R. R. Tykwinski, J. Am. Chem. Soc., 2005, 127, 2666.

8 (a) M. B. Nielsen and F. Diederich, Chem. Rev., 2005, 105, 1837; (b) J. Z. Liu, J. W. Y. Lam and B. Z. Tang, Chem. Rev., 2009, 109, 5799.

9 A. Stütz, Angew. Chem., Int. Ed., 1987, 26, 320.

10 D. Lechner, M. Stavri, M. Oluwatuyi, R. Perda-Miranda and S. Gibbons, Phytochemistry, 2004, 65, 331.

11 (a) R. Schmidt, R. Thorwirth, T. Szuppa, A. Stolle, B. Ondruschka and H. Hopf, Chem.-Eur. J., 2011, 17, 8129; (b) R. A. Xiao, R. Y. Yao and M. Z. Cai, Eur. J. Org. Chem., 2012, 22, 4178; (c) A. Narani, R. K. Marella, P. Ramudu, K. S. R. Rao and D. R. Burri, RSC Adv., 2014, 4, 3774.

12 M. L. Lerch, M. K. Harper and D. J. Faulkner, J. Nat. Prod., 2003, 66, 667.

13 (a) S. Morandi, F. Pellati, S. Benvenuti and F. Prati, Tetrahedron, 2008, 64, 6324; (b) S. F. Mayer, A. Steinreiber, R. V. A. Orru and K. Faber, J. Org. Chem., 2002, 67, 9115.

14 C. Glaser, Ber. Dtsch. Chem. Ges., 1869, 2, 422.

15 (a) H. L. Li, L. L. Wang, M. Yang and Y. X. Qi, Catal. Commun., 2012, 17, 179; (b) D. Saha, T. Chatterjee, M. Mukherjee and B. C. Ranu, J. Org. Chem., 2012, 77, 9379; (c) W. Shi, Y. D. Luo, X. C. Luo, L. Chao, H. Zhang, J. Wang and A. W. Lei, J. Am. Chem. Soc., 2008, 130, 14713; (d) Z. W. Chen, H. F. Jiang, A. Z. Wang and S. R. Yang, J. Org. Chem., 2010, 75, 6700; (e) S. Ahammed, D. Kundu and B. C. Ranu, J. Org. Chem., 2014, 79, 7391.

16 (a) J. R. Suárez, D. Collado-Sanz, D. J. Cárdenas and J. L. Chiara, J. Org. Chem., 2015, 80, 1098; (b) M. NasrEsfahani, I. Mohammadpoor-Baltork, A. R. Khosropour, M. Moghadam, V. Mirkhani, S. Tangestaninejad, V. Agabekov and H. A. Rudbaria, RSC Adv., 2014, 4, 14291; (c) Z. Y. Ma, X. Y. Wang, S. Y. Wei, H. L. Yang, F. W. Zhang, P. Wang, M. Xie and J. T. Ma, Catal. Commun., 2013, 39, 24. 
17 M. L. N. Rao, P. Dasgupta, B. S. Ramakrishna and V. N. Murty, Tetrahedron Lett., 2014, 55, 3529.

18 Y. Nishihara, K. Ikegashira, A. Mori and T. Hiyama, Tetrahedron Lett., 1998, 39, 4075.

19 A. Dermenci, R. E. Whittaker and G. Dong, Org. Lett., 2013, 15, 2242.

20 (a) Y. Kim, A. Park, K. Park and S. Lee, Tetrahedron Lett., 2011, 52, 1766; (b) J. Moon, M. Jeong, H. Nam, J. Ju, J. H. Moon, H. M. Jung and S. Lee, Org. Lett., 2008, 10, 945; (c) J. Moon, M. Jang and S. Lee, J. Org. Chem., 2009, 74, 1403; (d) K. Park, G. Bae, J. Moon, J. Choe, K. H. Song and S. Lee, J. Org. Chem., 2010, 75, 6244; (e) K. Pak, G. Bae, A. Park, Y. Kim, J. Choe, K. H. Song and S. Lee, Tetrahedron Lett., 2011, 52, 576.

21 (a) Y. G. Zhu, T. Xiong, W. Y. Han and Y. A. Shi, Org. Lett., 2014, 16, 6144; (b) G. Cahiez, C. Chaboche, F. MahuteauBetzer and M. Ahr, Org. Lett., 2005, 7, 1943; (c) A. Krasovskiy, A. Tishkov, V. del Amo, H. Mayr and P. Knochel, Angew. Chem., Int. Ed., 2006, 45, 5010.

22 D. X. Liu, F. L. Li, H. X. Li, J. Gao and J. P. Lang, Tetrahedron, 2014, 70, 2416.

23 For selected recent reports on the oxidative homocoupling reactions of terminal alkynes with the oxidants, see: $(a)$ H. L. Li, M. Yang, X. Zhang, L. Yan, J. Li and Y. X. Qi, New J. Chem., 2013, 37, 1343; (b) F. Alonso and M. Yus, ACS Catal., 2012, 2, 1441; (c) K. Yin, C. J. Li, J. Li and X. S. Jia, Green Chem., 2011, 13, 591; (d) R. A. Xiao, R. Y. Yao and M. Z. Cai, Eur. J. Org. Chem., 2012, 4178; (e) S. L. Zhang, X. Y. Liu and T. Q. Wang, Adv. Synth. Catal., 2011, 353, 1463; (f) W. Y. Yin, C. He, M. Chen, H. Zhang and A. W. Lei, Org. Lett., 2009, 11, 709; $(g)$ X. Meng, C. B. Li, B. C. Han, T. S. Wang and B. H. Chen, Tetrahedron, 2010, 66, 4029; (h) Y. G. Zhu and Y. A. Shi, Org. Biomol. Chem., 2013, 11, 7451; (i) J. R. Suárez, D. Collado-Sanz, D. J. Cárdenas and J. L. Chiara, J. Org. Chem., 2015, 80, 1098; (j) K. Fang, M. H. Xie, Z. N. Zhang, P. Ning and G. Y. Shu, Tetrahedron Lett., 2013, 54, 3819.

24 F. V. Singh, M. F. Z. J. Amaral and H. A. Stefani, Tetrahedron Lett., 2009, 50, 2636.
25 (a) K. Osowska, T. Lis and S. Szafert, Eur. J. Org. Chem., 2008, 27, 4598; (b) Z. Chen, H. Jiang, A. Wang and S. Yang, J. Org. Chem., 2010, 75, 6700.

26 Y. Nishihara, K. Ikegashira, K. Hirabayashi, J. Ando, A. Mori and T. Hiyama, J. Org. Chem., 2000, 65, 1780.

27 (a) B. Shrestha, S. Thapa, S. K. Gurung, R. A. S. Pike and R. Giri, J. Org. Chem., 2016, 81, 787; (b) D. F. Crépin and J. P. A. Harrity, Org. Lett., 2013, 15, 4222; (c) O. V. Larionov and E. J. Corey, Org. Lett., 2010, 12, 300; (d) W. Dávila, W. Torres and J. A. Prieto, Tetrahedron, 2007, 63, 8218; (e) M. Sasaki, K. Tanino and M. Miyashita, Org. Lett., 2001, 3, 1765; (f) M. Sasaki, M. Miyazawa, K. Tanino and M. Miyashita, Tetrahedron Lett., 1999, 40, 9267.

28 (a) B. M. Wang, M. Bonin and L. Micouin, Org. Lett., 2004, 6, 3481; (b) R. Chinchilla and C. Nàjera, Chem. Rev., 2007, 107, 874; (c) E.-I. Negishi and L. Anastasia, Chem. Rev., 2003, 103, 1979; (d) J. Kessabi, R. Beaudegnies, P. M Jung, B. Martin, F. Montel and S. Wendeborn, Synthesis, 2008, 4, 655; (e) H. Tanaka and Y. Shishido, Bioorg. Med. Chem. Lett., 2007, 17, 6079.

29 (a) D. B. Biradar and H. M. Gau, Chem. Commun., 2011, 47, 10467; (b) W. T. Shu, S. L. Zhou and H. M. Gau, Synthesis, 2009, 3, 4075; (c) S. L. Ku, X. P. Hui, C. A. Chen, Y. Y. Kuo and H. M. Gau, Chem. Commun., 2007, 3847.

30 D. B. Biradar and H. M. Gau, Org. Biomol. Chem., 2012, 10, 4243.

31 (a) J. Caeiro, J. P. Sestelo and L. A. S arandeses, Chem.-Eur. J., 2008, 14, 741; (b) I. Koyama, T. Kurahashi and S. Matsubara, J. Am. Chem. Soc., 2009, 131, 1350; (c) Y. Shi, J. Huang, Y. F. Yang, L. Y. Wu, Y. N. Niu, P. F. Huo, X. Y. Liu and Y. M. Liang, Adv. Synth. Catal., 2009, 351, 141; (d) J. Terao, F. Bando and N. Kambe, Chem. Commun., 2009, 7336; (e) S. Sako, T. Kurahashi and S. Matsubara, Chem. Commun., 2011, 47, 6150.

32 (a) Q. H. Li, J. Y. Jeng and H. M. Gau, Eur. J. Org. Chem., 2014, 31, 7531; (b) Q. H. Li, J. W. Liao, Y. L. Huang, R. T. Chiang and H. M. Gau, Org. Biomol. Chem., 2014, 12, 7634; (c) Q. H. Li and H. M. Gau, Synlett, 2012, 5, 747; (d) Q. H. Li, Y. Ding and X. J. Yang, Chin. Chem. Lett., 2014, 25, 1296. 